\title{
Associations among immunological, parasitological and clinical parameters in canine visceral leishmaniasis: Emaciation, spleen parasitism, specific antibodies and leishmanin skin test reaction
}

\author{
W.L.C. dos-Santos ${ }^{\text {a }}{ }^{*}$, E.E. Jesus ${ }^{\text {a }}$, M. Paranhos-Silva ${ }^{\text {b }}$, A.M. Pereira ${ }^{a}$, \\ J.C. Santos ${ }^{\text {a }}$, C.O. Baleeiro ${ }^{\text {a }}$, E.G. Nascimento ${ }^{\text {c }}$, E.D. Moreira ${ }^{\mathrm{a}}$, \\ G.G.S. Oliveira ${ }^{a}$, L.C. Pontes-de-Carvalho ${ }^{a}$

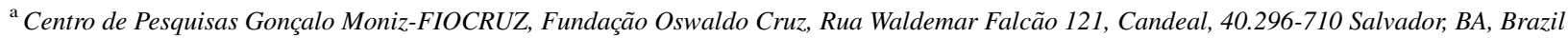 \\ ${ }^{\mathrm{b}}$ Instituto de Ciências da Saúde, Universidade Federal da Bahia, Av. Reitor Miguel Calmon s/n, Canela, 40110-100 Salvador, BA, Brazil \\ ${ }^{\mathrm{c}}$ Centro de Referência em Doenças Endêmicas Pirajá da Silva-PIEJ, CSU, URBIS 1, Rua 3 s/n, Jequié 45.200-000, BA, Brazil
}

Received 13 August 2007; received in revised form 27 December 2007; accepted 8 February 2008

\begin{abstract}
Associations among parameters commonly used as markers of infection by Leishmania sp., or of susceptibility to visceral leishmaniasis, were investigated in 325 stray dogs from an area where this disease is endemic. Evidence of infection (presence of Leishmania in splenic cultures, positive leishmanin skin test (LST) or detection of anti-Leishmania antibody activity in the serum) was found in $57 \%$ of the animals. Both evidence of weight loss $\left(\chi^{2}\right.$-test, $\left.P=0.0005\right)$ and presence of specific antibody activity in the serum $\left(\chi^{2}\right.$-test, $\left.P<0.0001\right)$ were directly associated with positive splenic culture. The frequencies of animals with positive splenic culture were directly correlated with the intensities of antibody activity in the serum as measured by ELISA (relative risk of 3.4 for animals with moderate antibody levels and relative risk of 8.43 for animals with high-antibody levels). A negative association was observed between positive leishmanin skin test results and emaciation $\left(\chi^{2}, P=0.0089\right)$. Furthermore, animals with positive splenic cultures and negative leishmanin skin test results had higher levels of total serum IgG (Kruskal-Wallis test, $P=0.001$ ) and IgG2 (Kruskal-Wallis test, $P=0.05$ ) than animals with negative splenic cultures, and were more emaciated than animals with negative LST results and positive splenic cultures. The data presented herein suggest that associating these common parameters may improve their performance in predicting susceptibility to canine visceral leishmaniasis.
\end{abstract}

(C) 2008 Elsevier B.V. All rights reserved.

Keywords: Leishmanin skin test; Canine visceral leishmaniasis; Leishmania chagasi; Leishmania infantum; Spleen; Immunoglobulin isotypes

\section{Introduction}

Leishmania chagasi/Leishmania infantum is the causal agent of human and canine visceral leishma-

\footnotetext{
* Corresponding author. Tel.: +55 713176 2262; fax: +557132562326.

E-mail address: wluis@bahia.fiocruz.br (W.L.C.dos-Santos).
}

niases (CVL) in Europe and America (Paranhos-Silva et al., 1996; Alvar et al., 1997). Recovery or resistance to these diseases is associated with cellular, and not humoral, immune responses (Carvalho et al., 1992; Alvar et al., 1997). A large effort has been made to identify resistance and susceptibility markers to visceral leishmaniasis in dogs, based on the profile of the antiparasite immune response in combination with clinical and parasitological data. The main parameters used to 
access the status of susceptibility or resistance in CVL are: (i) the presence of parasites in lymph nodes or internal organs (Pinelli et al., 1994; Paranhos-Silva et al., 2003; Gradoni et al., 2005; Lemesre et al., 2005); (ii) the parasite burden in different organs (Molano et al., 2003; Reis et al., 2006); (iii) the levels of specific antibodies (Pinelli et al., 1994; Paranhos-Silva et al., 2003); (iv) the specific antibody isotypes (Leandro et al., 2001; de Oliveira Mendes et al., 2003; Quinnell et al., 2003); (v) the leishmanin skin test (LST) reaction (Pinelli et al., 1994; Martinez-Moreno et al., 1995; Solano-Gallego et al., 2000; Borja-Cabrera et al., 2002; Molano et al., 2003); (vi) the intensity of in vitro lymphoproliferative response and cytokine production in the presence of Leishmania antigen (Pinelli et al., 1994; Santos-Gomes et al., 2002; Lemesre et al., 2005); and (viii) the presence of clinical signs of disease (Oliveira et al., 1993; Pinelli et al., 1994; MartinezMoreno et al., 1995; Leandro et al., 2001; ParanhosSilva et al., 2003; Gradoni et al., 2005; Reis et al., 2006). None of these parameters is definitive and the determination of some of them requires extensive laboratory work. This may be the reason why many studies on visceral leishmaniasis use serology, parasite identification, leishmanin skin test, and clinical data to assess the state of host immunity. The relationship between these tests with susceptibility to leishmaniasis has been defined in human beings (Badaro et al., 1986; Carvalho et al., 1992) and in murine models of visceral and cutaneous leishmaniasis (Honore et al., 1998; Melby et al., 2001; Guimaraes et al., 2006). The accurate interpretation of such parameters in CVL still requires additional study.

In this work, we studied the distribution of the following parameters in dogs naturally infected with L. chagasi: specific antibody activity in the serum, leishmanin skin test results, emaciation, and splenic parasitism. The study was aimed at determining the degree of concomitance of these parameters in individual animals. Our hypothesis was that parameters usually considered markers of susceptibility to CVL, such as spleen parasitism, emaciation and high levels of anti-Leishmania antibodies would be frequently found in the same animal and, conversely, such susceptibility markers would be absent or less intensely expressed in dogs with positive LST result (which is considered a marker of resistance to CVL by some authors). Understanding the distribution of these parameters in L. chagasiinfected animals may contribute to their more appropriate use in the evaluation of new therapies and candidate vaccines.

\section{Material and methods}

\subsection{Animals}

325 stray dogs of different breeds and estimated ages were collected from the streets of the town of Jequie (Bahia, Brazil), at different periods, between 1997 and 2006, in collaboration with the endemic disease surveillance program of the Bahia State Health Service. Visceral leishmaniasis is endemic to the urban area of Jequié (Dos Santos et al., 1993; Paranhos-Silva et al., 1996) and L. chagasi has been the only species isolated from dogs (Paranhos-Silva et al., 1996) and human beings (Paranhos-Silva et al., 2001) with the disease. The dogs were identified with sequential numbers and subjected to the tests/examinations described below. The animals were kept for at least $48 \mathrm{~h}$ in the municipal kennel. If Leishmania infection was confirmed or if the dogs were not claimed by their rightful owners, they were sacrificed as recommended by the Brazilian program for control of zoonotic diseases (http:// portal.saude.gov.br/portal/saude/visualizar_texto.cfm? idtxt=22139). All experiments were conducted in accordance with the Oswaldo Cruz Foundation guidelines for experimentation with animals (http://www. presidencia.fiocruz.br/vppdt1/com_etn_uso_anim_.php).

\subsection{Parasite antigens}

L. chagasi (MHOM/BR2000/Merivaldo2) and Leishmania amazonensis (Leila strain, MHOM/BR88/ BA-125) promastigotes were characterized by isoenzymes and reactivity with species-specific monoclonal antibodies (Dr. G. Grimaldi, Fundação Oswaldo Cruz, Rio de Janeiro). The parasites were grown in vitro using Schneider's medium (Gibco) containing 10\% of fetal calf serum (Cultlab). They were washed three times with $0.15 \mathrm{M}$ phosphate-buffered saline, $\mathrm{pH} 7.4$ (PBS) and lysed by repeated cycles of freezing and thawing followed by sonication. Antigen batches to be used in ELISA were processed in the presence of a combination of enzymatic inhibitors: $2 \mu \mathrm{g} / \mathrm{mL}$ of phenylmethanesulfonyl fluoride (PMSF), $2 \mu \mathrm{g} / \mathrm{mL}$ of $N$ - $p$-tosyl-Lphenylalanine chloromethyl ketone (TPCK), $2 \mu \mathrm{g} / \mathrm{mL}$ of $N$-alfa- $p$-tosyl-L-lysine chloromethyl ketone (TLCK), $2 \mu \mathrm{g} / \mathrm{mL}$ of 4-nitrophenyl $p^{\prime}$-guanidinobenzoate (NPGB) and $2 \mu \mathrm{g} / \mathrm{mL}$ of $N$-(trans-epoxysuccinyl)L-leucine 4-guanidinobutylamide; trans-3-carboxyoxirane-2-carbonyl-L-leucylagmatine; trans-epoxysuccinyl-L-leucylamido (4-gunidino) butane; L-trans-3carboxyoxiran-2-carbonyl-L-leucylagmatine (E64). Antigen batches to be used in the leishmanin skin tests 
were sterily prepared and no enzyme inhibitors or preserving agents were added. Antigen suspensions were stored at $-70{ }^{\circ} \mathrm{C}$ until use.

\subsection{Leishmanin skin test}

L. chagasi antigen was diluted in saline to a final concentration of $2.5 \mathrm{mg}$ of protein per $\mathrm{mL}$. Each animal was intradermally injected with $100 \mu \mathrm{L}$ volumes of the antigen solution at different sites of the abdominal skin (Baleeiro et al., 2006). As a control, $100 \mu \mathrm{L}$ of the diluent (saline) was injected at a different site on the abdominal skin. Forty-eight hours after the injections, the sizes of indurations were measured by observers without previous knowledge of the site of injections. In order to reduce experimental variations, both the tests and their readings were always performed by the same two authors (WLCS and MPS for the leishmanin injection; WLCS and GGSO for the readings). The readings were aided by the use of a ballpoint pen. A cellotape stamp of the measured area was always taken and preserved in the experimental book, for eventual confirmation if necessary. The results are expressed as the mean of the two largest perpendicular axes of the induration area. Skin reactions with induration size equal or larger than $5 \mathrm{~mm}$ were considered positive.

\subsection{Anti-Leishmania antibody activity in the serum}

This was measured by ELISA as previously described (Baleeiro et al., 2006). Briefly, 96-well plates were sensitized with crude antigen obtained from $L$. amazonensis or L. chagasi. The plates were washed, blocked with PBS containing 10\% of skimmed milk, and the serum of each animal was applied at the dilution of 1:400, followed by an anti-dog total IgG peroxidase conjugate (Sigma). The enzymatic reaction was developed with tetramethyl benzidine (Sigma). A cutoff was established using serum samples obtained from 48 animals from Porto Alegre (Rio Grande do Sul State, Brazil) and from Salvador (Bahia State, Brazil). Both Salvador and Porto Alegre are non-endemic areas for visceral leishmaniasis. The mean \pm S.D. of the antiLeishmania antibody activity in the serum of this group of animals was $0.117 \pm 0.052$ with Gaussian distribution (Kolmogorov-Smirnov test, 0.062). Values greater than the mean plus three S.D. values of the results obtained from 48 health dogs were considered positive. The measurements of IgG1 and IgG2 anti-Leishmania antibodies in the serum were performed using an ELISA similar to the one described above, with the following modification: horseradish peroxidase-anti-dog IgG1 or
anti-IgG2 conjugates, both produced in goat and supplied by Bethyl Laboratories Inc., replaced the anti-total IgG conjugate. All measurements were performed in duplicate and the results were confirmed in another independent assay.

A group of 203 animals (all animals from number 31 to 249 for which serum samples were available) were comparatively examined for their serum anti-Leishmania antibody activity. In order to allow for a more accurate comparison among blood samples tested at different periods, minimizing the occurrence of problems such as variability among assays and loss of reactivity of stored sera, the following procedures were adopted: (1) a pool of sera collected from three dogs naturally infected with $L$. chagasi, having high titers of anti-Leishmania specific antibody, was added in quadruplicate and used to normalize results between assays. This pool of sera was used at the dilution corresponding to the middle point titer of its antiLeishmania antibody activity. Among these 203 animals, the intensity of anti-Leishmania antibody response in the serum varied between 10 and $406 \%$ of the O.D. values obtained using the reference pool of positive sera. (2) In order to control for the preservation of the serum samples, the results obtained in these tests were compared with those obtained during the initial tests performed at the moment of capture of the animals. No decrease in serum reactivity was observed. Following these measurements the animals were distributed into four categories according with the intensity of antibody response: negative serology: relative O.D. $\leq 60 \%$; positive low: relative O.D. of 61-120\%; positive intermediate: relative O.D. of 121$180 \%$ and positive high: relative O.D. $\geq 181 \%$.

\subsection{Parasite isolation in cultures}

Immediately after sacrifice, splenic samples were collected from the animals by puncture using an $18 \mathrm{G} \times 38 \mathrm{~mm}$ gauge needle connected to a $20-\mathrm{mL}$ syringe. Spleen aspirates were cultured in biphasic agar-blood-Schneider's medium, supplemented with $10 \%$ fetal bovine serum as previously described (Paranhos-Silva et al., 2003). Cultures were examined weekly for identification of promastigotes, and examinations continued for a period lasting up to 2 months if they remained negative.

\subsection{Nutritional status}

Animals were assigned to two categories of nutritional status: (i) with evidence of emaciation (if 
prominence of bones of vertebral column, iliac crest, and ribs was present); (ii) normal (if bone prominence was absent).

\subsection{Expression and significance of the results}

Numerical data are shown in tables and graphs, representing absolute values, means or proportions when stated. The significance of the differences among the means of the groups was tested using the KruskalWallis test. When the test was found significant, the difference between two groups was identified using Dunn's Multiple Comparison test (Glantz, 1997). For comparisons involving proportions, the $\chi^{2}$-test with Yates' correction or Fisher's exact probability test were used when recommended. The critical level of significance was established at $P \leq 0.05 \%$.

\section{Results}

\subsection{Main characteristics of the animals used in the study}

Among the 278 animals for which gender was recorded, $167(60.1 \%)$ were male and $111(39.9 \%)$ were female. Nutritional status was recorded for 301 animals and signs of weight loss were observed in 122 (40.5\%) (Table 1).

\subsection{Evidence of natural infection by Leishmania}

We considered as evidence of Leishmania infection the presence of a positive splenic culture, positive serology or positive LST result.

Splenic cultures were performed in 282 animals and were positive for Leishmania in 84 (29.8\%).

Table 1

Characteristics of the population of 325 stray dogs from an endemic area of infection caused by $L$. chagasi

\begin{tabular}{|c|c|c|}
\hline Parameter & $N$ & $\%$ \\
\hline \multicolumn{3}{|l|}{ Gender } \\
\hline Male & 167 & 60.1 \\
\hline Female & 111 & 39.9 \\
\hline Total & 278 & 100 \\
\hline \multicolumn{3}{|l|}{ Signs of infection/disease } \\
\hline Emaciation $(\mathrm{EN}=301)^{\mathrm{a}}$ & 122 & 40.5 \\
\hline Positive spleen culture $(\mathrm{EN}=282)$ & 84 & 29.8 \\
\hline Positive ELISA (EN = 307) & 132 & 43.0 \\
\hline Positive leishmanin skin test $(\mathrm{EN}=282)$ & 44 & 15.6 \\
\hline
\end{tabular}

${ }^{\text {a }}$ Total number of animals examined in each category.
The presence of anti-Leishmania antibody activity was investigated in the sera of 307 animals and was positive in $132(43 \%)$. The values of optical density in the ELISA performed with the serum of the 203 comparatively examined animals varied from 10 to $406 \%$ of that observed with a reference positive serum. The distribution of the values were, however, nonGaussian (KS distance $=0.207, P<0.001)$, skewed to the right (Pearson's skewness index $=1.829 \pm 0.171$ ), and displayed no obvious bimodal profile. The median was $47 \%$, the 25 th percentile was $26 \%$ and the 75 th percentile was $85 \%$. The values were distributed into categories of negative, low, intermediate or high optical densities as follows: $127(62.6 \%)$ were negative (relative O.D. $\leq 60), 41(20.2 \%)$ were low positive (relative O.D. of 61-120); 14 (6.9\%) were intermediate positive (relative O.D. of 120-180) and 21 (10.3\%) were high positive (Table 2).

The leishmanin skin test was performed in 282 animals (Table 1). Induration areas of $2.5-12.5 \mathrm{~mm}$ were observed in 61 animals (21.6\%), and in 44 (15.6\%) of the animals, the induration areas were equal to or larger than $5 \mathrm{~mm}$.

Evidence of Leishmania infection (positive splenic culture, serology or LST) was present in $171(54.1 \%)$ of the 316 animals subjected to at least one of the tests. Among the 252 dogs subjected to all three tests (splenic culture, serology and LST), 109 (43.2\%) were negative in all and $143(56.8 \%)$ were positive in at least one of these tests (Fig. 1).

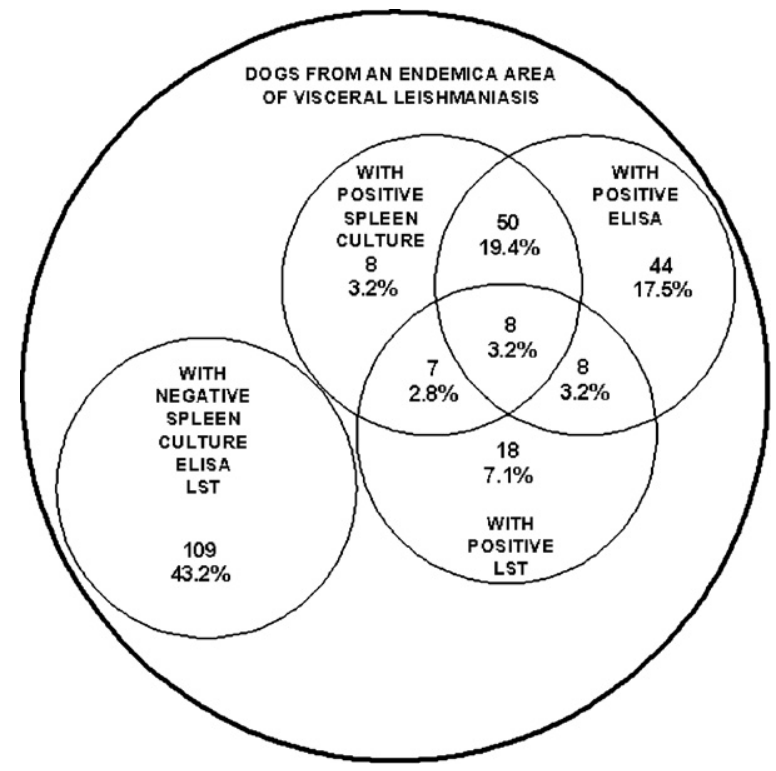

Fig. 1. Distribution of dogs from an endemic area of visceral leishmaniasis according to different markers of infection and immunity to the disease. LST = leishmanin skin test. 
Table 2

Distribution of dogs from an endemic area of visceral leishmaniasis according to the intensity of the anti-Leishmania antibody response and the leishmanin skin test

\begin{tabular}{|c|c|c|c|c|c|c|}
\hline \multirow[t]{2}{*}{ Immunological test } & \multirow[t]{2}{*}{$N$} & \multicolumn{2}{|c|}{ Spleen culture } & \multirow[t]{2}{*}{ Prevalence ratio } & \multirow[t]{2}{*}{ 95\% C.I. } & \multirow[t]{2}{*}{$P$-value } \\
\hline & & Total & $\%$ & & & \\
\hline \multicolumn{7}{|l|}{ Serological categories (O.D.\%) } \\
\hline Negative $(0-60)$ & 127 & $12 / 113$ & 10.7 & & & \\
\hline Positive low (61-120) & 41 & $8 / 38$ & 21.1 & 1.98 & $0.88-4.48$ & 0.1724 \\
\hline Positive intermediate (121-180) & 14 & $4 / 12$ & 33.3 & 3.14 & $1.20-8.22$ & 0.0476 \\
\hline Positive high (181-406) & 21 & $17 / 19$ & 89.5 & 8.43 & $4.83-14.70$ & $<10^{-6}$ \\
\hline \multicolumn{7}{|l|}{ LST categories (average axis) ${ }^{\mathrm{a}}$} \\
\hline Negative $(0.0-4.9 \mathrm{~mm})$ & 238 & $59 / 216$ & 27.3 & & & \\
\hline Positive low (5.0-9.9 mm) & 33 & $15 / 33$ & 45.5 & 1.33 & $0.97-1.84$ & 0.0550 \\
\hline Positive high (10.0-12.5 mm) & 11 & $2 / 11$ & 18.2 & 0.89 & $0.66-1.19$ & 0.7505 \\
\hline
\end{tabular}

Relationship with splenic parasitism.

${ }^{\text {a }}$ LST: leishmanin skin test.

\subsection{Associations between findings}

The associations between each of the studied parameters (sex, emaciation, spleen parasitism, positive
LST result or serology against Leishmania antigens) are shown in Table 3 and Fig. 1.

No significant associations involving gender were observed (Table 3 ).

Table 3

Distribution and association of infection/disease markers in stray dogs from an endemic area of visceral leishmaniasis caused by $L$. chagasi

\begin{tabular}{|c|c|c|c|c|c|c|c|c|}
\hline & \multicolumn{2}{|l|}{ Gender } & \multicolumn{2}{|l|}{ ELISA } & \multicolumn{2}{|l|}{ Emaciation } & \multicolumn{2}{|l|}{$\mathrm{LST}^{\mathrm{a}}$} \\
\hline & Male $(\%)$ & Female $(\%)$ & $+(\%)$ & $-(\%)$ & $+(\%)$ & $-(\%)$ & $+(\%)$ & $-(\%)$ \\
\hline \multicolumn{9}{|c|}{ Spleen culture } \\
\hline+ & $50(34)$ & $29(29)$ & $64(53)^{*}$ & $17(11)$ & $46(42) * * *$ & $35(22)$ & 17 (39) & $59(27)$ \\
\hline- & $96(66)$ & $70(71)$ & $56(46)$ & 137 (89) & $63(58)$ & $126(78)$ & $27(61)$ & 157 (73) \\
\hline Total & $146(100)$ & 99 (100) & $120(100)$ & $154(100)$ & 109 (100) & $161(100)$ & $44(100)$ & $216(100)$ \\
\hline \multicolumn{9}{|l|}{ ELISA } \\
\hline+ & $72(45)$ & $46(44)$ & & & $60(51)^{* *}$ & $64(37)$ & $16(39)$ & $102(44)$ \\
\hline- & $89(55)$ & $59(56)$ & & & $58(49)$ & 107 (63) & $25(61)$ & $130(56)$ \\
\hline Total & $161(100)$ & $105(100)$ & & & $118(100)$ & $171(100)$ & $41(100)$ & $232(100)$ \\
\hline \multicolumn{9}{|l|}{ Emaciation } \\
\hline+ & $60(37)$ & 47 (45) & $60(48) * *$ & $58(35)$ & & & $9(21)^{* * * *}$ & 99 (44) \\
\hline- & $101(73)$ & $58(55)$ & $64(52)$ & $107(65)$ & & & 34 (79) & $128(56)$ \\
\hline Total & $161(100)$ & $105(100)$ & $124(100)$ & 165 (100) & & & $43(100)$ & 227 (100) \\
\hline \multicolumn{9}{|l|}{$\mathrm{LST}^{\mathrm{a}}$} \\
\hline+ & 27 (18) & $11(12)$ & $16(14)$ & $25(16)$ & $9(8) * * * *$ & $34(21)$ & & \\
\hline- & $123(82)$ & $83(88)$ & $102(86)$ & $130(84)$ & 99 (92) & $128(79)$ & & \\
\hline Total & $150(100)$ & 94 (100) & $118(100)$ & 155 (100) & $108(100)$ & $162(100)$ & & \\
\hline \multicolumn{9}{|l|}{ Gender } \\
\hline Male & & & $72(61)$ & $89(60)$ & $60(56)$ & $101(64)$ & $27(71)$ & $123(60)$ \\
\hline Female & & & $46(39)$ & $59(40)$ & 47 (44) & $58(36)$ & $11(29)$ & $83(40)$ \\
\hline Total & & & $118(100)$ & 148 (100) & $107(100)$ & $159(100)$ & $38(100)$ & $206(100)$ \\
\hline
\end{tabular}

$* P<0.0001, * * P=0.032, * * * P=0.0005$ and $* * * * P=0.0089$.

${ }^{\text {a }}$ LST = leishmanin' skin test. $\chi^{2}$-test. 
Table 4

Anti-Leishmania antibody activity in the serum and cases of emaciation in dogs with parasites in the spleen and negative or positive leishmanin' skin test from an endemic area for visceral leishmaniasis

\begin{tabular}{|c|c|c|c|c|c|c|c|c|c|c|c|c|}
\hline \multirow{3}{*}{$\begin{array}{l}\text { Spleen } \\
\text { culture }\end{array}$} & \multirow[t]{3}{*}{$\mathrm{LST}^{\mathrm{a}}$} & \multicolumn{9}{|c|}{ Anti-Leishmania antibody activity in the serum } & \multirow[t]{3}{*}{ Emaciation $^{\mathrm{d}}$} & \multirow[t]{3}{*}{$\%$} \\
\hline & & \multicolumn{3}{|c|}{ Total $\mathrm{IgG}^{\mathrm{b}}$} & \multicolumn{3}{|l|}{$\operatorname{IgG}^{\mathrm{c}}$} & \multicolumn{3}{|l|}{$\operatorname{IgG} 2^{c}$} & & \\
\hline & & Median & {$[25-75 \%]$} & $N$ & MEDIAN & {$[25 \%-75 \%]$} & $N$ & Median & {$[25 \%-75 \%]$} & $N$ & & \\
\hline- & - & 38.5 & [24.0-64.0] & 104 & 0.22 & {$[0.17-0.51]$} & 7 & 0.47 & {$[0.25-1.26]$} & 8 & $55 / 151$ & 36 \\
\hline- & + & 44.0 & {$[24.0-73.5]$} & 23 & 0.19 & {$[0.16-0.35]$} & 11 & 0.91 & [0.58-1.39] & 11 & $6 / 26$ & 23 \\
\hline+ & + & 52.5 & {$[38.0-117.5]$} & 10 & 0.20 & {$[0.17-0.25]$} & 8 & 0.84 & [0.66-1.19] & 8 & $3 / 17$ & 18 \\
\hline+ & - & 179.0 & [77.0-215.0] & $25^{\mathrm{e}}$ & 0.21 & {$[0.15-0.81]$} & 19 & 1.51 & {$[1.20-1.55]$} & $19^{\mathrm{f}}$ & $37 / 56$ & $66^{\mathrm{g}}$ \\
\hline
\end{tabular}

${ }^{\text {a }} \mathrm{LST}=$ leishmanin skin test.

b The O.D. expressed as the median and 25 th and 75 th percentiles of the relative values obtained using a pool of positive serum as reference.

c The O.D. is expressed as the median and the 25 th and 75 th percentiles of the absolute values.

d The number of animals with emaciation and total examined in each category.

e Significantly higher than the than the groups with negative spleen culture (Kruskal-Wallis test, $P<0.001$ ).

f Significantly higher than the than the groups with negative spleen culture (Kruskal-Wallis test, $P<0.05$ ).

g Proportion is significantly higher than that observed the other groups $\left(\chi^{2}\right.$-test, $\left.P=0.0001\right)$.

A positive anti-Leishmania ELISA result was associated with a positive splenic culture; a positive splenic culture was observed in $64(53 \%)$ out of 120 animals with positive serology and in 17 (11\%) out of 154 animals with negative serology ( $\chi^{2}$-test, $P<0.0001)$. The frequency of animals with positive spleen parasitism increased with each change in category of anti-Leishmania antibody activity in the serum (Table 2): positive splenic culture was observed in $12 / 113(10.7 \%)$ of the animals with negative serology; in $8 / 38(21.1 \%)$ of the animals in the lowpositive category; in $4 / 12(33.3 \%)$ of the animals in the intermediate-positive category; and in $17 / 19(89.5 \%)$ in the high-positive category. The prevalence ratios were significantly higher for animals with intermediatepositive $(3.14, P=0.0476)$ or high-positive serology (8.43, $P<10^{-6}$ ) than for animals in the other categories.

Positive serology was also associated with emaciation (Table 3). Evidence of weight loss was present in 60 $(48 \%)$ out of 124 animals with positive ELISA and in 58 $(35 \%)$ out of 165 animals with negative serology $\left(\chi^{2}-\right.$ test, $P=0.032$ ).

Emaciation was associated with positive splenic culture. Among the 109 dogs with evidence of weight loss, $46(42 \%)$ had a positive splenic culture and among the 161 animals without emaciation, 35 (22\%) had positive splenic culture $\left(P<0.0005, \chi^{2}\right.$-test $)$. Emaciation was also inversely associated with positive LST results: only nine $(8.3 \%)$ out of the 108 animals with emaciation had a positive LST result, while $34(21 \%)$ out of 162 animals without evidence of weight loss had a positive LST result $\left(\chi^{2}-\right.$ test, $P=0.0089$ ).
No other significant association was observed between LST results and the other variables in the whole group of animals. Although the frequency of dogs with positive splenic culture appears to increase in animals with induration diameters between 5 and $9.9 \mathrm{~mm}$, declining in animals with larger induration areas (Table 2), such differences were not statistically significant. In order to examine in more detail the relationship between LST results and Leishmania infection, we further investigated the association between LST results and other immunological parameters (total $\mathrm{IgG}, \mathrm{IgG} 1$ and $\mathrm{IgG} 2$ anti-Leishmania antibody activity in the serum) and emaciation, in animals with or without spleen parasitism.

As shown in Table 4, the animals with positive splenic culture and negative LST results had higher antiLeishmania antibody activity in serum, both for total IgG (Kruskal-Wallis test, $P<0.001$ ) and IgG2 (Kruskal-Wallis test, $P<0.001$ ), than the animals with positive LST without splenic parasitism or than the animals that were negative both in the LST and splenic cultures. Animals with a positive splenic culture and a negative LST result also displayed emaciation more frequently $\left(\chi^{2}\right.$-test, $\left.P<0.0001\right)$ than the animals of other groups.

\section{Discussion}

In this work, we examined the relationships among several parameters commonly used as markers of Leishmania infection and susceptibility to CVL. We found statistically significant associations of positive serology with both positive splenic culture for Leishmania and emaciation, indicating that positive 
serology could be considered a marker for both infection and susceptibility to CVL. On the other hand, positive LST results were negatively associated with emaciation. In addition, animals with splenic parasitism only had significantly high anti-Leishmania antibody activity in the serum and higher frequency of emaciation when they were negative in the LST. Such findings suggest that the presence of an LST reaction may indicate that the immune system is controlling the infection even in animals with a positive splenic culture.

The association between positive serology and active parasitism in different organs has been reported in the literature (Killick-Kendrick et al., 1994; Ashford et al., 1995; Ozensoy et al., 1998; Paranhos-Silva et al., 2003; Barrouin-Melo et al., 2004, 2006; Baleeiro et al., 2006). We extended this observation by showing an exponential increase in the frequency of spleen parasitism paralleling the increased levels of antiLeishmania antibodies in the serum. One possible explanation for this finding is that the parasite burden may determine the intensity of the antibody response (Reis et al., 2006), either by increasing the availability of minor parasite epitopes, such that a larger number of B lymphocytes are stimulated (Rhalem et al., 1999), or by favoring the development of an antibody-producing Th2 immune response (Bretscher et al., 1992). It is interesting to note that, in this work, 17 (11\%) animals with negative serology had detectable Leishmania in their spleens. This finding may indicate either that those animals were at an initial stage of the infection, i.e., they had not yet developed the antibody response, or that they had a sub-clinical infection, in which splenic cultures were intermittently positive (Paranhos-Silva et al., 2003). In fact, 9 of the 17 animals with negative ELISA and positive splenic culture showed no evidence of weight loss, in contrast to the association that was observed between positive serology and emaciation in the entire group of animals with spleen parasitism.

In this series, $48 \%$ of the animals with positive serology were underweight. This prevalence is higher than that reported for dogs referred to veterinary clinics (Amusategui et al., 2003). Although CVL leads to weight loss and caquexia (Pearson et al., 1990, 1992), a fact that has been confirmed in this study, other causes of emaciation, such as malnutrition and other infections (Andreotti et al., 2006; Barrouin-Melo et al., 2006; Trapp et al., 2006), should be considered in the present study. In fact, signs of weight loss were found in $33 \%$ of the animals with negative serology and negative splenic culture. Longitudinal studies are necessary in order to investigate the potential for other infections and malnutrition to increase the CVL susceptibility of stray animals in endemic areas.

It is interesting to note that the associations of emaciation with spleen parasitism and positive serology were absent in animals with positive LST results, and that an inverse association was found between LST reactions and underweight status. These findings may reflect either an impairment of cellular immune response secondary to emaciation or a causal effect of disease progression on both immune energy and nutritional impairment. In order to evaluate whether the presence of the skin cellular hypersensitivity to Leishmania antigens would reflect changes in other parameters of immunity to the parasite, we examined the distribution of total IgG, IgG1 and IgG2 antiLeishmania antibodies in these animals. Negative LST results were associated with higher levels of specific antibodies in the serum, especially for the $\mathrm{IgG} 2$ isotype in Leishmania-infected animals. Such observations seems to be in disagreement with Solano-Gallego and collaborators' results (2000), who found an association between specific IgG levels and LST results in a population of Ibizian hounds. Such disagreement may be due to genetic or phenotypic differences in the studied populations and/or differences in the interpretation of LST results. Erythematous responses without induration were considered positive by Solano-Gallego and collaborations' results (2000) and negative in our study.

Although a clear dichotomy of $\operatorname{IgG} 1 / \operatorname{IgG} 2 \mathrm{a}$ antibody response to Leishmania antigens is found in mice (Guimaraes et al., 2006), this is not well defined in dogs. Whereas most studies show an increase in IgG2 antiLeishmania antibody activity in infected dogs (Deplazes et al., 1995; Bourdoiseau et al., 1997; Nieto et al., 1999; Leandro et al., 2001; Solano-Gallego et al., 2001; Almeida et al., 2005), the data on IgG1 antibodies is more controversial (Deplazes et al., 1995; Cavaliero et al., 1999; Solano-Gallego et al., 2001; Reis et al., 2006). In fact, Quinnell et al. (2003), using a set of monoclonal antibodies, were not able to demonstrate a clear polarity in antibody response in infected animals. In our study, we found an elevation of $\operatorname{IgG} 2$ antiLeishmania antibodies in infected dogs, very similar to that observed with the total $\mathrm{IgG}$, but not a clear association between IgG1 and infection or emaciation. Taken together, these data suggest that, if a dichotomous pattern of antibody isotypes exists in CVL, their determinants must be complex and do not lead to a clear-cut association with clinical status, presence of parasite in tissues or cellular hypersensitivity to Leishmania antigens. Studies on the comparability of 
the reagents used for the detection of IgG isotypes in dogs may help to solve some of the discrepancies observed among different studies.

\section{Conclusions}

(1) Our data confirm the associations between serology and active parasitism and the presence of clinical signs of disease in L. chagasi-infected dogs;

(2) Our results show that the frequency of spleen parasitism increases with a relative risk of 8.43 in animals with high levels of anti-Leishmania antibody in the serum;

(3) Our study also shows that Leishmania-infected dogs with negative LST results have positive serology and emaciation more frequently than Leishmaniainfected dogs with positive LST.

\section{Acknowledgments}

This work was supported by the Brazilian Ministry of Science and Technology (Brazilian National Research Council - CNPq, grant no. 521260/98-1, and PRONEX) and FAPESB.

\section{References}

Almeida, M.A., Jesus, E.E., Sousa-Atta, M.L., Alves, L.C., Berne, M.E., Atta, A.M., 2005. Antileishmanial antibody profile in dogs naturally infected with Leishmania chagasi. Vet. Immunol. Immunopathol. 106, 151-158.

Alvar, J., Canavate, C., Gutierrez-Solar, B., Jimenez, M., Laguna, F., Lopez-Velez, R., Molina, R., Moreno, J., 1997. Leishmania and human immunodeficiency virus coinfection: the first 10 years. Clin. Microbiol. Rev. 10, 298-319.

Amusategui, I., Sainz, A., Rodriguez, F., Tesouro, M.A., 2003. Distribution and relationships between clinical and biopathological parameters in canine leishmaniasis. Eur. J. Epidemiol. 18, 147-156.

Andreotti, R., Oliveira, J.M., Silva, E.A., Oshiro, L.M., Matos, M.D., 2006. Occurrence of Neospora caninum in dogs and its correlation with visceral leishmaniasis in the urban area of Campo Grande, Mato Grosso do Sul, Brazil. Vet. Parasitol. 135, 375-379.

Ashford, D.A., Bozza, M., Freire, M., Miranda, J.C., Sherlock, I., Eulalio, C., Lopes, U., Fernandes, O., Degrave, W., Barker Jr., R.H., et al., 1995. Comparison of the polymerase chain reaction and serology for the detection of canine visceral leishmaniasis. Am. J. Trop. Med. Hyg. 53, 251-255.

Badaro, R., Jones, T.C., Lorenco, R., Cerf, B.J., Sampaio, D., Carvalho, E.M., Rocha, H., Teixeira, R., Johnson Jr., W.D., 1986. A prospective study of visceral leishmaniasis in an endemic area of Brazil. J. Infect. Dis. 154, 639-649.

Baleeiro, C.O., Paranhos-Silva, M., Dos Santos, J.C., Oliveira, G.G., Nascimento, E.G., de Carvalho, L.P., dos-Santos, W.L., 2006. Montenegro's skin reactions and antibodies against different Leishmania species in dogs from a visceral leishmaniosis endemic area. Vet. Parasitol. 139, 21-28.
Barrouin-Melo, S.M., Larangeira, D.F., de Andrade Filho, F.A., Trigo, J., Juliao, F.S., Franke, C.R., Palis Aguiar, P.H., dos-Santos, W.L.C., Pontes-de-Carvalho, L., 2006. Can spleen aspirations be safely used for the parasitological diagnosis of canine visceral leishmaniosis? A study on assymptomatic and polysymptomatic animals. Vet. J. 171, 331-339.

Barrouin-Melo, S.M., Larangeira, D.F., Trigo, J., Aguiar, P.H., dosSantos, W.L., Pontes-de-Carvalho, L., 2004. Comparison between splenic and lymph node aspirations as sampling methods for the parasitological detection of Leishmania chagasi infection in dogs. Mem. Inst. Oswaldo Cruz 99, 195-197.

Borja-Cabrera, G.P., Correia Pontes, N.N., da Silva, V.O., Paraguai de Souza, E., Santos, W.R., Gomes, E.M., Luz, K.G., Palatnik, M., Palatnik de Sousa, C.B., 2002. Long lasting protection against canine kala-azar using the FML-QuilA saponin vaccine in an endemic area of Brazil (Sao Goncalo do Amarante, RN). Vaccine 20, 3277-3284.

Bourdoiseau, G., Bonnefont, C., Hoareau, E., Boehringer, C., Stolle, T., Chabanne, L., 1997. Specific IgG1 and IgG2 antibody and lymphocyte subset levels in naturally Leishmania infantuminfected treated and untreated dogs. Vet. Immunol. Immunopathol. 59, 21-30.

Bretscher, P.A., Wei, G., Menon, J.N., Bielefeldt-Ohmann, H., 1992. Establishment of stable, cell-mediated immunity that makes "susceptible" mice resistant to Leishmania major. Science 257, $539-542$.

Carvalho, E.M., Barral, A., Pedral-Sampaio, D., Barral-Netto, M., Badaro, R., Rocha, H., Johnson Jr., W.D., 1992. Immunologic markers of clinical evolution in children recently infected with Leishmania donovani chagasi. J. Infect. Dis. 165, 535-540.

Cavaliero, T., Arnold, P., Mathis, A., Glaus, T., Hofmann-Lehmann, R., Deplazes, P., 1999. Clinical, serologic, and parasitologic follow-up after long-term allopurinol therapy of dogs naturally infected with Leishmania infantum. J. Vet. Intern. Med. 13, 330334.

de Oliveira Mendes, C., Paraguai de Souza, E., Borja-Cabrera, G.P., Maria Melo Batista, L., Aparecida dos Santos, M., Ellner Parra, L., Menz, I., Palatnik, M., Palatnik de Sousa, C.B., 2003. IgG1/ $\mathrm{IgG} 2$ antibody dichotomy in sera of vaccinated or naturally infected dogs with visceral leishmaniosis. Vaccine 21, 25892597.

Deplazes, P., Smith, N.C., Arnold, P., Lutz, H., Eckert, J., 1995. Specific IgG1 and IgG2 antibody responses of dogs to Leishmania infantum and other parasites. Parasite Immunol. 17, 451-458.

Dos Santos, A.J., Nascimento, E.G., Silva, M.P., De Carvalho, L.C., 1993. Report on a visceral and cutaneous leishmaniases focus in the town of Jequie, State of Bahia, Brazil. Rev. Inst. Med. Trop. Sao Paulo 35, 583-584.

Glantz, S.A., 1997. Primer of Bio-Statistics, fourth ed. McGraw-Hill, $473 \mathrm{pp}$.

Gradoni, L., Foglia Manzillo, V., Pagano, A., Piantedosi, D., De Luna, R., Gramiccia, M., Scalone, A., Di Muccio, T., Oliva, G., 2005. Failure of a multi-subunit recombinant leishmanial vaccine (MML) to protect dogs from Leishmania infantum infection and to prevent disease progression in infected animals. Vaccine 23, 5245-5251.

Guimaraes, E.T., Santos, L.A., Ribeiro Dos Santos, R., Teixeira, M.M., Dos Santos, W.L., Soares, M.B., 2006. Role of interleukin-4 and prostaglandin E(2) in Leishmania amazonensis infection of BALB/c mice. Microb. Infect. 8, 1219-1226.

Honore, S., Garin, Y.J., Sulahian, A., Gangneux, J.P., Derouin, F., 1998. Influence of the host and parasite strain in a mouse model of 
visceral Leishmania infantum infection. FEMS Immunol. Med. Microbiol. 21, 231-239.

Killick-Kendrick, R., Killick-Kendrick, M., Pinelli, E., Del Real, G., Molina, R., Vitutia, M.M., Canavate, M.C., Nieto, J., 1994. A laboratory model of canine leishmaniasis: the inoculation of dogs with Leishmania infantum promastigotes from midguts of experimentally infected phlebotomine sandflies. Parasite 1, 311-318.

Leandro, C., Santos-Gomes, G.M., Campino, L., Romao, P., Cortes, S., Rolao, N., Gomes-Pereira, S., Rica Capela, M.J., Abranches, P., 2001. Cell mediated immunity and specific IgG1 and IgG2 antibody response in natural and experimental canine leishmaniosis. Vet. Immunol. Immunopathol. 79, 273-284.

Lemesre, J.L., Holzmuller, P., Cavaleyra, M., Goncalves, R.B., Hottin, G., Papierok, G., 2005. Protection against experimental visceral leishmaniasis infection in dogs immunized with purified excreted secreted antigens of Leishmania infantum promastigotes. Vaccine 23, 2825-2840.

Martinez-Moreno, A., Moreno, T., Martinez-Moreno, F.J., Acosta, I., Hernandez, S., 1995. Humoral and cell-mediated immunity in natural and experimental canine leishmaniasis. Vet. Immunol. Immunopathol. 48, 209-220.

Melby, P.C., Chandrasekar, B., Zhao, W., Coe, J.E., 2001. The hamster as a model of human visceral leishmaniasis: progressive disease and impaired generation of nitric oxide in the face of a prominent Th1-like cytokine response. J. Immunol. 166, 1912-1920.

Molano, I., Alonso, M.G., Miron, C., Redondo, E., Requena, J.M., Soto, M., Nieto, C.G., Alonso, C., 2003. A Leishmania infantum multi-component antigenic protein mixed with live BCG confers protection to dogs experimentally infected with L. infantum. Vet. Immunol. Immunopathol. 92, 1-13.

Nieto, C.G., Garcia-Alonso, M., Requena, J.M., Miron, C., Soto, M., Alonso, C., Navarrete, I., 1999. Analysis of the humoral immune response against total and recombinant antigens of Leishmania infantum: correlation with disease progression in canine experimental leishmaniasis. Vet. Immunol. Immunopathol. 67, 117-130.

Oliveira, G.G., Santoro, F., Sadigursky, M., 1993. The subclinical form of experimental visceral leishmaniasis in dogs. Mem. Inst. Oswaldo Cruz 88, 243-248.

Ozensoy, S., Ozbel, Y., Turgay, N., Alkan, M.Z., Gul, K., GilmanSachs, A., Chang, K.P., Reed, S.G., Ozcel, M.A., 1998. Serodiagnosis and epidemiology of visceral leishmaniasis in Turkey. Am. J. Trop. Med. Hyg. 59, 363-369.

Paranhos-Silva, M., Freitas, L.A., Santos, W.C., Grimaldi, G.J., Pontes-de-Carvalho, L.C., Oliveira-dos-Santos, A.J., 1996. A cross-sectional serodiagnostic survey of canine leishmaniasis due to Leishmania chagasi. Am. J. Trop. Med. Hyg. 55, 39-44.

Paranhos-Silva, M., Oliveira, G.G., Reis, E.A., de Menezes, R.M., Fernandes, O., Sherlock, I., Gomes, R.B., Pontes-de-Carvalho, L.C., dos-Santos, W.L., 2003. A follow-up of Beagle dogs intra- dermally infected with Leishmania chagasi in the presence or absence of sand fly saliva. Vet. Parasitol. 114, 97-111.

Paranhos-Silva, M., Pontes-de-Carvalho, L.C., de Sa Oliveira, G.G., Nascimento, E.G., dos-Santos, W.L., 2001. Skin reactions to thimerosal and Leishmania in dogs from a leishmaniasis endemic area: it is better to keep them apart. Mem. Inst. Oswaldo Cruz 96, 679-681.

Pearson, R.D., Cox, G., Evans, T., Smith, D.L., Weidel, D., Castracane, J., 1990. Wasting and macrophage production of tumor necrosis factor/cachectin and interleukin 1 in experimental visceral leishmaniasis. Am. J. Trop. Med. Hyg. 43, 640-649.

Pearson, R.D., Cox, G., Jeronimo, S.M., Castracane, J., Drew, J.S., Evans, T., de Alencar, J.E., 1992. Visceral leishmaniasis: a model for infection-induced cachexia. Am. J. Trop. Med. Hyg. 47, 8-15.

Pinelli, E., Killick-Kendrick, R., Wagenaar, J., Bernadina, W., del Real, G., Ruitenberg, J., 1994. Cellular and humoral immune responses in dogs experimentally and naturally infected with Leishmania infantum. Infect. Immunol. 62, 229-235.

Quinnell, R.J., Courtenay, O., Garcez, L.M., Kaye, P.M., Shaw, M.A., Dye, C., Day, M.J., 2003. IgG subclass responses in a longitudinal study of canine visceral leishmaniasis. Vet. Immunol. Immunopathol. 91, 161-168.

Reis, A.B., Teixeira-Carvalho, A., Vale, A.M., Marques, M.J., Giunchetti, R.C., Mayrink, W., Guerra, L.L., Andrade, R.A., CorreaOliveira, R., Martins-Filho, O.A., 2006. Isotype patterns of immunoglobulins: hallmarks for clinical status and tissue parasite density in Brazilian dogs naturally infected by Leishmania (Leishmania) chagasi. Vet. Immunol. Immunopathol. 112, 102-116.

Rhalem, A., Sahibi, H., Guessous-Idrissi, N., Lasri, S., Natami, A., Riyad, M., Berrag, B., 1999. Immune response against Leishmania antigens in dogs naturally and experimentally infected with Leishmania infantum. Vet. Parasitol. 81, 173-184.

Santos-Gomes, G.M., Rosa, R., Leandro, C., Cortes, S., Romao, P., Silveira, H., 2002. Cytokine expression during the outcome of canine experimental infection by Leishmania infantum. Vet. Immunol. Immunopathol. 88, 21-30.

Solano-Gallego, L., Llull, J., Ramos, G., Riera, C., Arboix, M., Alberola, J., Ferrer, L., 2000. The Ibizian hound presents a predominantly cellular immune response against natural Leishmania infection. Vet. Parasitol. 90, 37-45.

Solano-Gallego, L., Riera, C., Roura, X., Iniesta, L., Gallego, M., Valladares, J.E., Fisa, R., Castillejo, S., Alberola, J., Ferrer, L., Arboix, M., Portus, M., 2001. Leishmania infantum-specific IgG, IgG1 and IgG2 antibody responses in healthy and ill dogs from endemic areas. Evolution in the course of infection and after treatment. Vet. Parasitol. 96, 265-276.

Trapp, S.M., Dagnone, A.S., Vidotto, O., Freire, R.L., Amude, A.M., de Morais, H.S., 2006. Seroepidemiology of canine babesiosis and ehrlichiosis in a hospital population. Vet. Parasitol. 140, 223-230. 